\title{
Effect of Microstructure on the Localized Corrosion and Stress Corrosion Behaviours of Plasma-Electrolytic-Oxidation-Treated AA7075 Aluminum Alloy Forging in 3.5 wt. \% NaCl Solution
}

\author{
A. Venugopal,, ${ }^{1}$ Rajiv Panda, ${ }^{1}$ Sushant Manwatkar, ${ }^{1}$ K. Sreekumar, ${ }^{1}$ \\ L. Ramakrishna, ${ }^{2}$ and G. Sundararajan ${ }^{2}$ \\ ${ }^{1}$ Materials and Metallurgy Group, Material Characterization Division, Vikram Sarabhai Space Centre, \\ Thiruvananthapuram 695 022, India \\ ${ }^{2}$ International Advanced Research Centre for Powder Metallurgy and New Materials, Hyderabad 500 005, India
}

Correspondence should be addressed to A. Venugopal, arjun_venu@hotmail.com

Received 23 October 2011; Revised 30 December 2011; Accepted 17 January 2012

Academic Editor: Omar S. Es-Said

Copyright ( 2012 A. Venugopal et al. This is an open access article distributed under the Creative Commons Attribution License, which permits unrestricted use, distribution, and reproduction in any medium, provided the original work is properly cited.

\begin{abstract}
The influence of metallurgical heterogeneities such as coring and intermetallic phases on the corrosion and stress corrosion cracking behaviours of AA7075 aluminium alloy forging was examined in $3.5 \mathrm{wt}$. \% $\mathrm{NaCl}$ solution with and without plasma electrolytic oxidation coating. Electrochemical test results demonstrated significant improvement in the corrosion resistance of the alloy after PEO coating. Stress corrosion results show that the metallurgical heterogeneities resulted in a loss in elongation of the uncoated sample in $\mathrm{NaCl}(11.5 \%)$ when compared to the one tested in air (12.9\%). The loss in elongation of the uncoated sample was shown to be due to localized corrosion-assisted mechanical cracking rather than true stress corrosion based on preexposure tensile tests followed by posttest metallographic observation of the stress corrosion tested samples. This was further confirmed by the fractographic examination of the failed samples, which exhibited a typical ductile cracking morphology for all the coated and uncoated specimens.
\end{abstract}

\section{Introduction}

High-strength, precipitation hardened aluminium alloys such as AA7075 are widely used in aerospace industries in view of the good stress corrosion cracking (SCC) resistance in T7 temper conditions [1-5]. Although this treatment offered good improvement in the SCC resistance, localized corrosion such as pitting remains a problem in commercial aluminum alloys containing intermetallic phases such as $\mathrm{Al}_{7} \mathrm{Cu}_{2} \mathrm{Fe},(\mathrm{Al}, \mathrm{Cu})_{6}(\mathrm{Fe}, \mathrm{Cu})$, and $\mathrm{Mg}_{2} \mathrm{Si}$. Hence several studies were directed towards understanding the influence of these phases on the galvanic corrosion of aluminum. Among these phases, $\mathrm{Al}_{7} \mathrm{Cu}_{2} \mathrm{Fe}$ was reported to be the most cathodic phase, which results in the development of pitting at the particle-matrix interface [6]. These pits were the initiation sites for fatigue crack resulting in premature failure of AA7075T7351 alloy [7].
On this aspect, surface modification techniques such as laser surface melting (LSM) and plasma electrolytic oxidation (PEO) are widely employed for improving the corrosion resistance of light alloys such as aluminum and magnesium. Yue et al. [8] obtained significant improvement in the SCC resistance for 7075 aluminum alloy using excimer laser treatment. With respect to PEO, although this treatment was well proven towards enhancing the corrosion and wear resistance of aluminum alloys, the influence of such coating on the SCC resistance was not studied in detail. However, available results on the magnesium alloys indicated good improvement in the SCC resistance of AM50 magnesium alloy [9]. The same authors in another study reported only a marginal improvement for other alloys such as AZ61 [10] and AZ31HP alloys [11] by this coating. In spite of the above improvement, this coating could not completely prevent the SCC of those alloys. 
Yet another problem is the cast structure resulting from inadequate homogenisation and improper working especially in the case of large forgings, which can also lead to localised corrosion similar to that of intermetallic phases. Hence, understanding the influence of these metallurgical heterogeneities on the localised corrosion as well as SCC resistance is of scientific importance. The interest behind the SCC investigation of this alloy was to understand the effect of cast structure on the mechanical behaviour although this alloy exhibits good SCC resistance in T7 temper condition. This was studied in the coated and uncoated condition using polarization and SSRT tests in $3.5 \mathrm{wt}, \% \mathrm{NaCl}$ solution.

\section{Experimental Procedures}

2.1. Material. The substrate material used in the present investigation was AA7075-T7352 aluminium alloy forging, having the chemical composition (wt. \%) 1.2-2.0 Cu, 5.1-6.1 Zn, 2.1-2.9 Mg, Si-0.15 max, Mn-0.1 max, and Fe-0.2 max. Mn-0.1 max. Cr-0.18-0.28 and Ti-0.1 max. Cast billet of $300 \mathrm{~mm}$ diameter and $400 \mathrm{~mm}$ height was used as an input material. The cast billet was further processed through series of forging operations involving number of preheatings for realization of components to the required dimension. The resulting forged material was solution treated at $470^{\circ} \mathrm{C}$ for $36 \mathrm{~h}$ and water quenched to room temperature. Subsequently the forging was stress-relieved by compression treatment (2$5 \%$ ) followed by two-step aging at $107^{\circ} \mathrm{C}$ for $8 \mathrm{~h}$ and $177^{\circ} \mathrm{C}$ for $8 \mathrm{~h}$, respectively. Standard flat rectangular specimens having effective gauge dimensions of $30 \mathrm{~mm} \times 6 \mathrm{~mm} \times 4 \mathrm{~mm}$ were used for tensile tests, which were tested at a crosshead speed of $2 \mathrm{~mm} / \mathrm{s}$. The mechanical properties of this alloy in the above heat-treated condition were $0.2 \% \mathrm{YS}=320 \mathrm{MPa}$, $\mathrm{UTS}=425 \mathrm{MPa}$, and El. $\%=11.2$.

2.2. PEO Coating Formation. An alkali silicate solution $(4 \mathrm{~g} / \mathrm{L}$ KOH: $2 \mathrm{~g} / \mathrm{L} \mathrm{Na}_{2} \mathrm{SiO}_{3}$ ) was used as an electrolyte, and coating deposition was carried out at a constant current density of $0.2 \mathrm{~A} / \mathrm{cm}^{2}$ using a specially designed $50 \mathrm{~Hz}$ frequency AC high-voltage power supply. The temperature of the electrolyte was maintained constant at $35^{\circ} \mathrm{C}$ using a heat exchanger throughout the coating process. The treatment time of the samples was $30 \mathrm{~min}$. The samples were taken out of the electrolyte, thoroughly washed in cold running water, ultrasonically cleaned in the acetone medium, and dried.

\subsection{Microstructure and Phase Analysis. For microstructural} observations of the base metal, samples were sectioned and polished down to $5 \mu \mathrm{m}$ alumina finish followed by etching in Keller's reagent $\left(5 \mathrm{~mL} \mathrm{HNO}_{3}, 3 \mathrm{~mL} \mathrm{HCl}, 2 \mathrm{~mL} \mathrm{HF}\right.$, and $190 \mathrm{~mL}$ distilled water) and examined under optical microscope. The thickness of the coating was measured under SEM using metallographic cross-section of the coated sample. Xray diffraction analysis was performed using PANalytical model X-ray diffractometer with $\mathrm{Cu}-\mathrm{K} \alpha$ radiation between $30^{\circ}$ and $120^{\circ}$ to identify the phases present in the coating. Similar measurements were performed on AA7075 alloy without coating for comparison purpose.

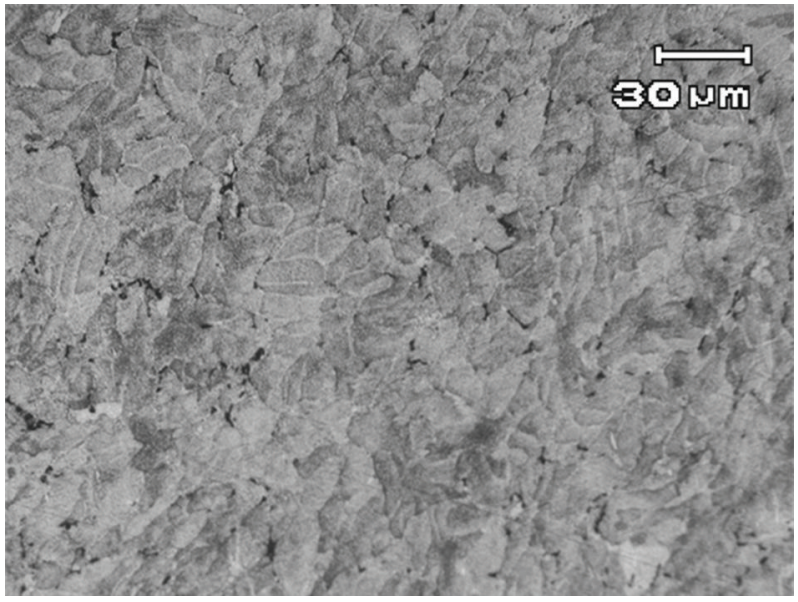

FIgURE 1: Optical micrograph of AA7075-T7352 alloy forging.

2.4. Electrochemical Corrosion Tests. Corrosion resistance of the PEO-coated and uncoated specimens was evaluated through potentiodynamic polarization tests using computercontrolled Zhaner IM6ex electrochemical workstation. The corrosion behaviour was examined in $3.5 \mathrm{wt}$. \% NaCl solution using reagent grade $\mathrm{NaCl}$ salt and deionized water. Tests were carried out using a standard three-electrode setup with $\mathrm{Pt}$ as counterelectrode and saturated calomel electrode (SCE) as a reference. A scan rate of $0.5 \mathrm{mV} / \mathrm{s}$ was used for polarization tests starting from a value of $300 \mathrm{mV}$ below the corrosion potential.

2.5. Slow Strain Rate Tensile (SSRT) Tests. Tests were carried out as per ASTM G129 at a strain rate of $5 \times 10^{-7} / \mathrm{s}$ for both coated and uncoated samples in air and $3.5 \mathrm{wt} . \% \mathrm{NaCl}$ as reference and corrosive environments, respectively. For uncoated specimens, tests were also carried out by preexposing the tensile specimens in the corrosive environment without any load for a period that corresponded to SSRT test duration, followed by testing in air after cleaning thoroughly in distilled water. This data along with the metallographic observations of the failed specimens gave information on whether pitting played any role in lowering the mechanical property of the specimens. A minimum of two samples was tested in all cases. SSRT was performed using CORTEST make CERT tensile testing machine using Perspex containers to hold the specimen in the environment. Similar specimens as used in tensile tests were used for SCC tests in which the PEO coating was provided within the gauge length. Before coating, the gauge length portion of the samples was polished up to 1000 grit $\mathrm{SiC}$ paper on all the sides to obtain a smooth surface and were degreased and ultrasonically cleaned in acetone. The average elongation of the specimen was measured by a pair of linear variable displacement transducers (LVDT) positioned on both sides of the specimen. Galvanic corrosion of the specimen and the grip material was avoided by using silicone rubber sealant by coating the interface between the specimen and grip portions. The elongation values measured in air and environment were used to assess 


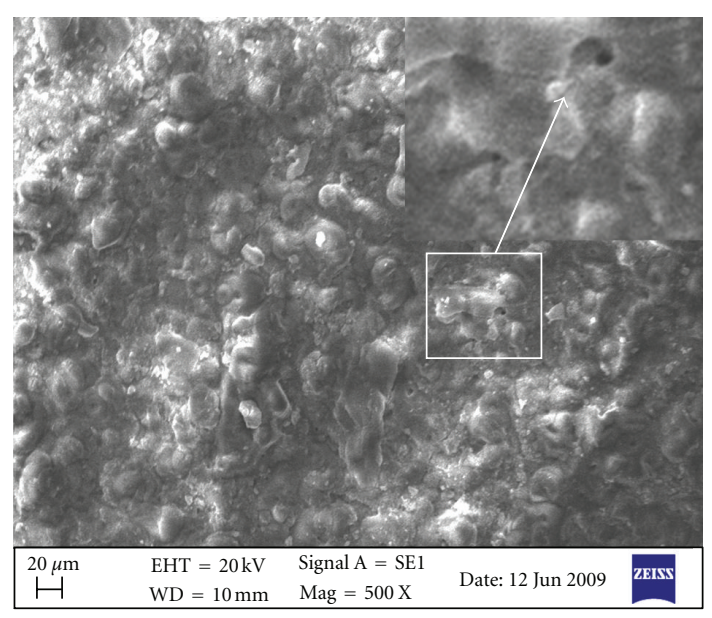

(a)

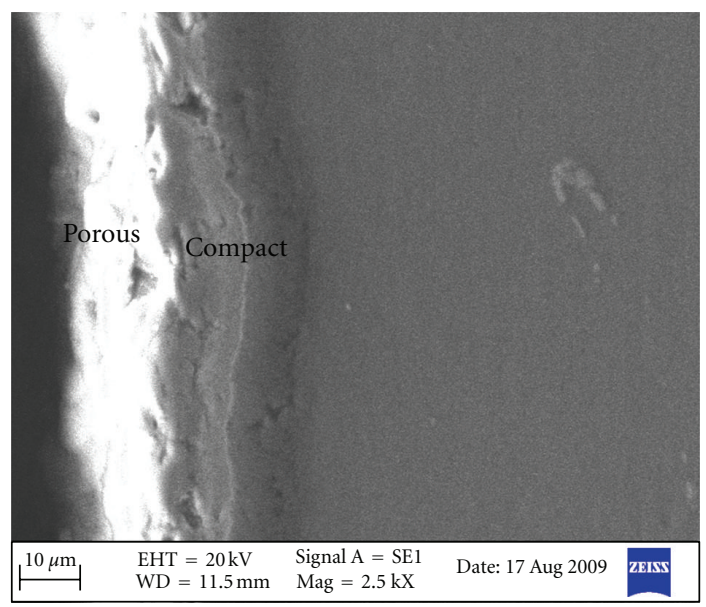

(b)

FIGURE 2: SEM micrographs showing (a) surface morphology of the PEO coating and (b) cross-section of the coated AA7075 alloy.

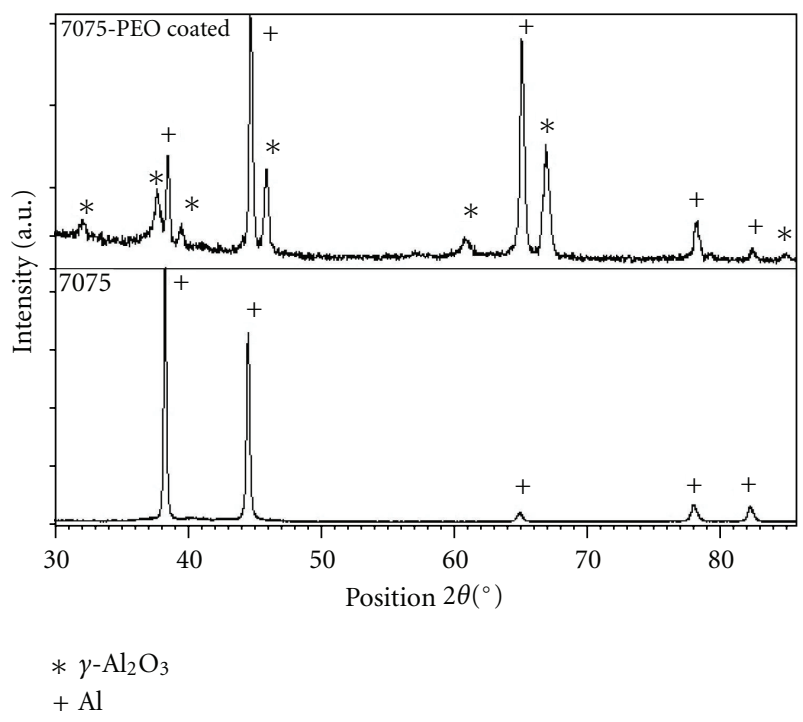

Figure 3: X-ray spectra of PEO coating formed on AA7075 alloy and base alloy.

the environmentally assisted cracking susceptibility of both coated and uncoated alloy forgings.

\section{Results and Discussion}

3.1. Microstructure and Coating Morphology. Figure 1 shows the microstructure of AA7075 alloy forging which evidently shows the dendritic structure due to inadequate working of the forging. Second phase particles seen as black in colour can be noted and are distributed randomly in the $\alpha$ - $\mathrm{Al} \mathrm{ma-}$ trix. These particles were reported as $\mathrm{Al}_{7} \mathrm{Cu}_{2} \mathrm{Fe},(\mathrm{Al}, \mathrm{Cu})_{6}$ $(\mathrm{Fe}, \mathrm{Cu})$, and so forth [6]. The surface morphology and crosssection of the ceramic alumina coating generated on this alloy were further observed under scanning electron microscope and are presented in Figure 2. Micropores of diameter

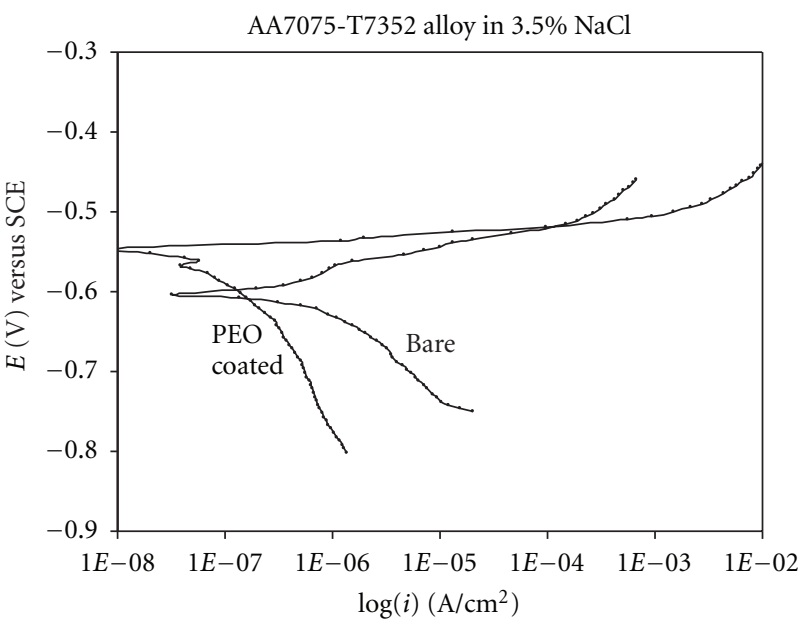

Figure 4: Potentiodynamic polarization plots obtained for the uncoated and PEO-coated AA7075 alloy in $3.5 \mathrm{wt}$ \% $\mathrm{NaCl}$ solution.

less than $2 \mu \mathrm{m}$ are evident on the coating and are characteristic of such PEO coatings [12]. Presence of numerous discharge channels and the rapidly solidified alumina can be seen on the surface of the coating (Figure 2(a)). The crosssectional SEM image of the coated sample shows that the coating thickness is $20 \mu \mathrm{m}$ (Figure 2(b)). Two distinct regions consisting of outer porous layer $(10 \mu \mathrm{m})$ and inner compact layer $(10 \mu \mathrm{m})$ can also be noted, which is in agreement with reported results of similar PEO coatings.

3.2. Phase Analysis. X-ray diffraction (XRD) pattern obtained for AA7075 alloy and the PEO coating generated on this alloy are presented in Figure 3. Analysis of the XRD spectra revealed that the component of the coating layer is mainly $\gamma$ $\mathrm{Al}_{2} \mathrm{O}_{3}$. The presence of aluminium peak could be due to the penetration of X-rays into the substrate. This may partly be due to the presence of pores in the coating as has been 


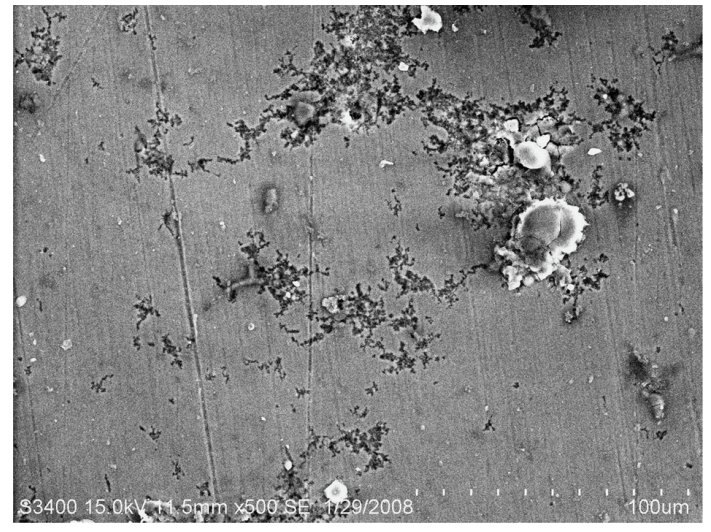

(a)

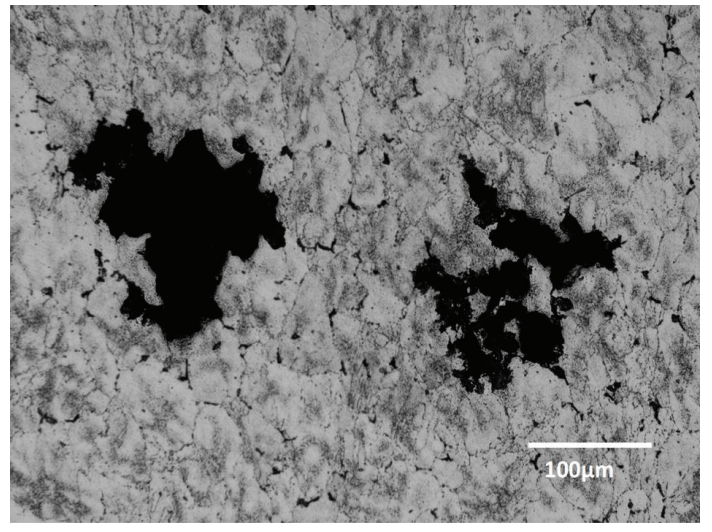

(b)

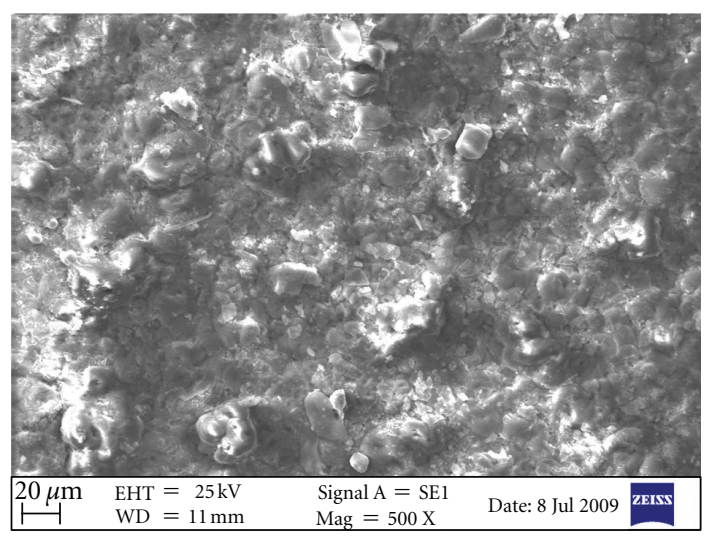

(c)

FIGURE 5: Corrosion morphology of the 7075 alloy observed after polarization test: (a) uncoated, (b) uncoated after polishing and etching, and (c) PEO coated.

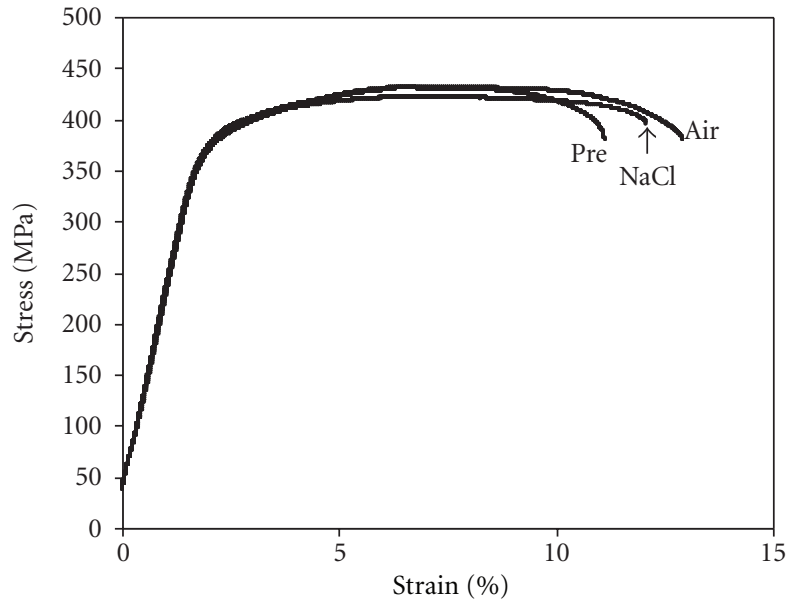

(a)

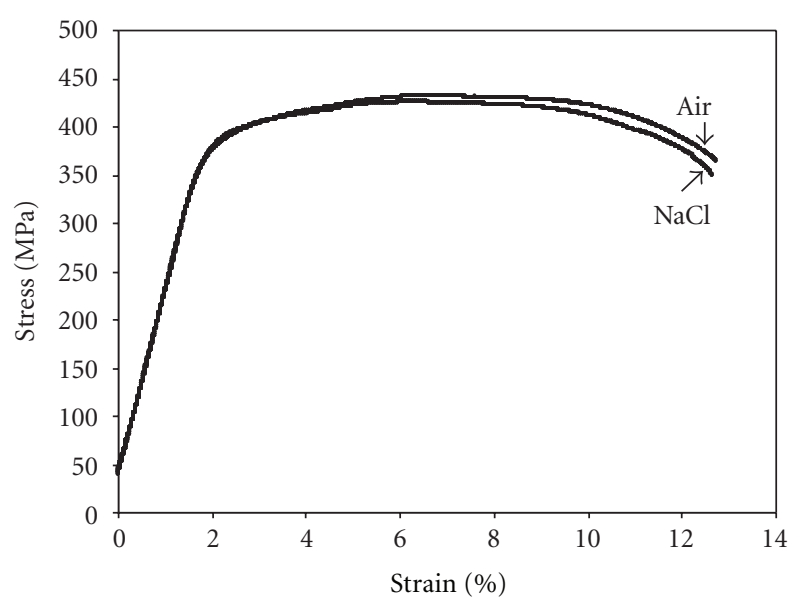

(b)

FIGURE 6: Stress versus \% strain plots obtained for (a) uncoated and (b) PEO-coated AA7075-T7352 aluminum alloy specimens in 3.5 wt. \% $\mathrm{NaCl}$ solution at a strain rate of $5 \times 10^{-7} / \mathrm{s}$. 


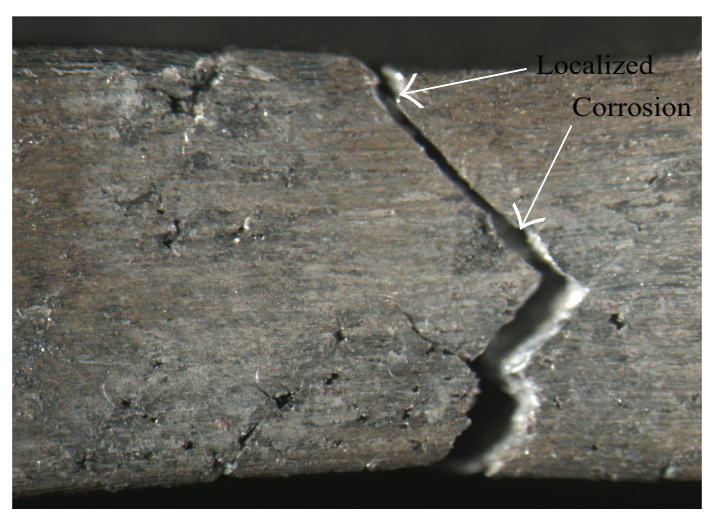

(a)

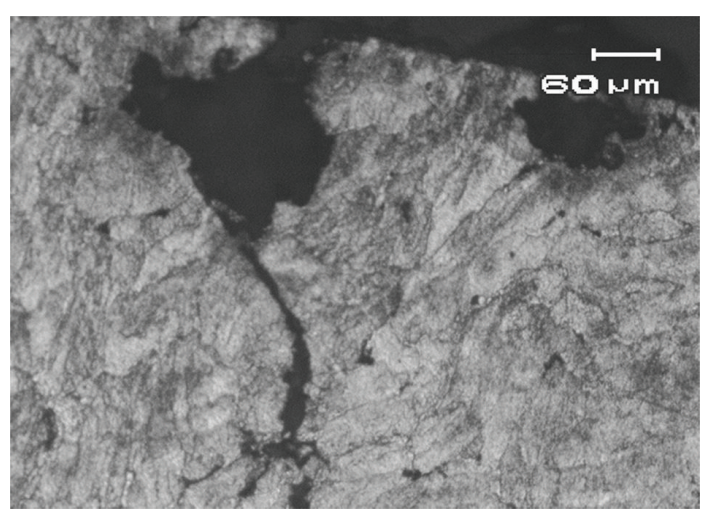

(b)

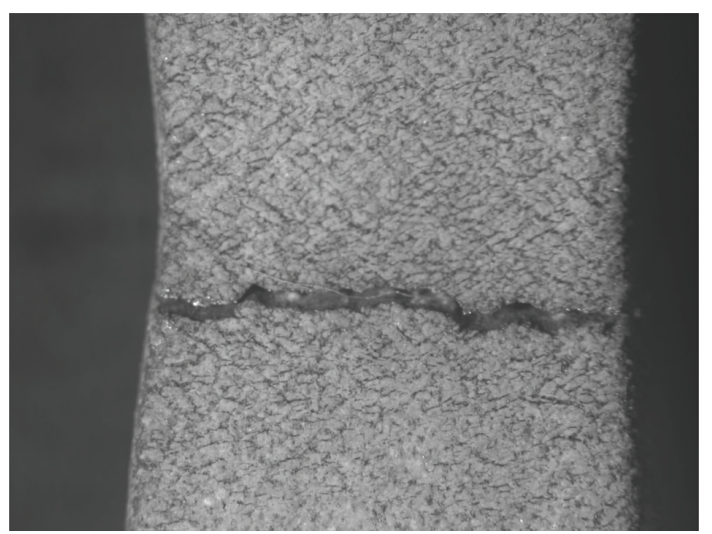

(c)

FIGURE 7: Stereo photomicrographs showing (a) localized pitting on the uncoated alloy, (b) crack initiation from localized corrosion, and (c) absence of pitting on the PEO-coated AA7075 aluminum alloy surface after SSRT (mag. 20x for (a) and (c).

reported by other investigators [13]. With respect to the phase content of the coating, while the present study revealed only $\gamma-\mathrm{Al}_{2} \mathrm{O}_{3}$, reported results on other aluminium alloys showed the presence of both $\alpha$ and $\gamma-\mathrm{Al}_{2} \mathrm{O}_{3}$ phases together $[14,15]$. Reported results indicate that $\gamma-\mathrm{Al}_{2} \mathrm{O}_{3}$ phase prevails in the early stage of coating process and gets transformed to $\alpha-\mathrm{Al}_{2} \mathrm{O}_{3}$ depending on the cooling rate. It was also sug-gested that alloying elements such as $\mathrm{Mg}, \mathrm{Cu}$, and $\mathrm{Zn}$ ions diffused from the substrate increase the transformation temperature of $\gamma$ to $\alpha-\mathrm{Al}_{2} \mathrm{O}_{3}$ resulting in lower $\alpha-\mathrm{Al}_{2} \mathrm{O}_{3}$ content. Among the three elements, $\mathrm{Mg}$ was shown to exhibit dominant effect towards increasing the transition temperature of $\gamma$ to $\alpha-\mathrm{Al}_{2} \mathrm{O}_{3}$ phase. This was shown to be due to the lower $\mathrm{Mg}-\mathrm{O}$ bond energy of $166 \mathrm{KJ} \mathrm{mol}^{-1}$ for $\mathrm{Mg}-\mathrm{O}$ when compared to $280 \mathrm{KJ} \mathrm{mol}^{-1}$ bond energy for Al-O. This in turn reduced the amount of alumina that transforms into the alpha phase during each plasma event. Hence, the absence of the $\alpha-\mathrm{Al}_{2} \mathrm{O}_{3}$ in the present study can be attributed to the higher content of magnesium and $\mathrm{Zn}$ in the substrate as these elements suppress the transformation of $\gamma$ to $\alpha \mathrm{Al}_{2} \mathrm{O}_{3}$ phase.

3.3. Electrochemical Corrosion. The polarization curves obtained for the uncoated and PEO-coated AA7075 aluminium alloy in $3.5 \mathrm{wt} . \% \mathrm{NaCl}$ solution are displayed in Figure 4.
An examination of the polarization plots shows that the corrosion potential $\left(E_{\text {corr }}\right)$ of the uncoated sample is more active $(-0.6 \mathrm{~V})$ and the resultant corrosion current density $\left(i_{\text {corr }}\right)$ also was high $\left(0.5 \mu \mathrm{A} / \mathrm{cm}^{2}\right)$ compared to the PEO-coated samples $\left(0.045 \mu \mathrm{A} / \mathrm{cm}^{2}\right)$. This indicated a reduction in $i_{\text {corr }}$ of the base metal by an order of magnitude as a result of $20 \mu \mathrm{m}$ PEO alumina coating on this alloy.

Observation of the sample after polarization tests revealed severe localized corrosion of the case of uncoated sample (Figure 5(a)) and the same after light polishing and etching indicated irregular pitting as a result of the dislodgment of the dendritic core along with second phase particles (Figure 5(b)). The absence of localized corrosion on the PEO-coated specimen indicated the good barrier property of the PEO coating as it offered corrosion protection for the base alloy (Figure 5(c)). Such coating did not allow the environment to diffuse through the coating, which otherwise results in galvanic couple formation with the second phases present in the matrix resulting in severe localized corrosion promoted by dendritic coring and second phases as observed in the case of uncoated alloy. Xue et al. [16] through elemental analysis across the cross-section of the coating performed after corrosion tests detected the presence of chloride ions only on the porous layer and not on 


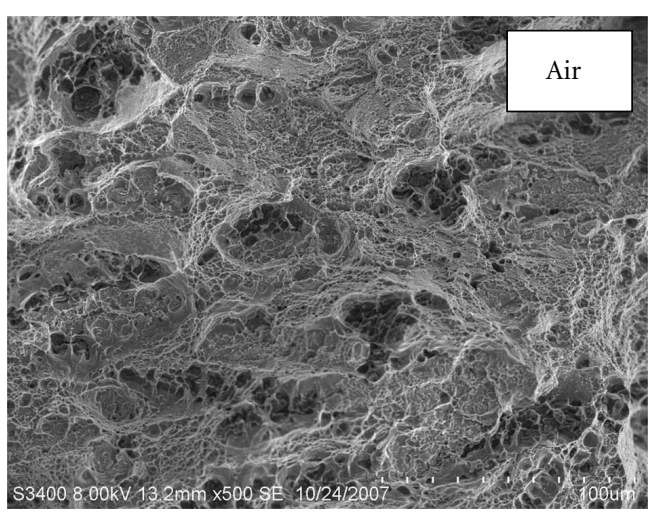

(a)

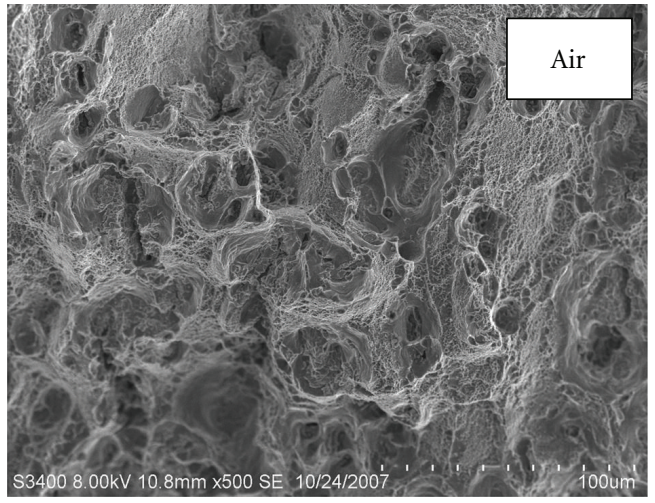

(c)

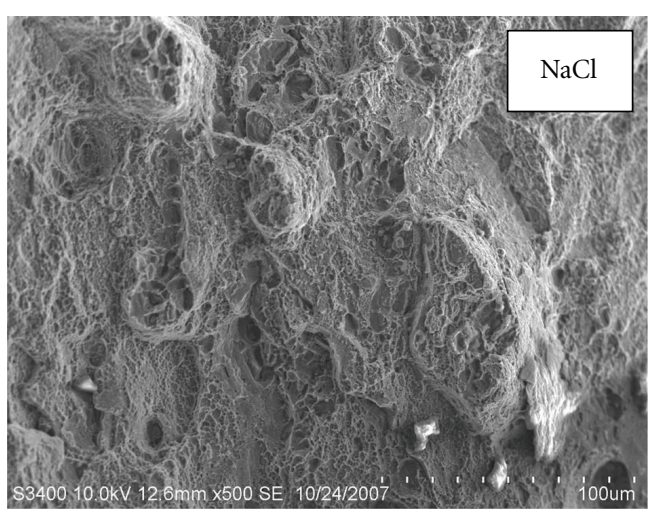

(b)

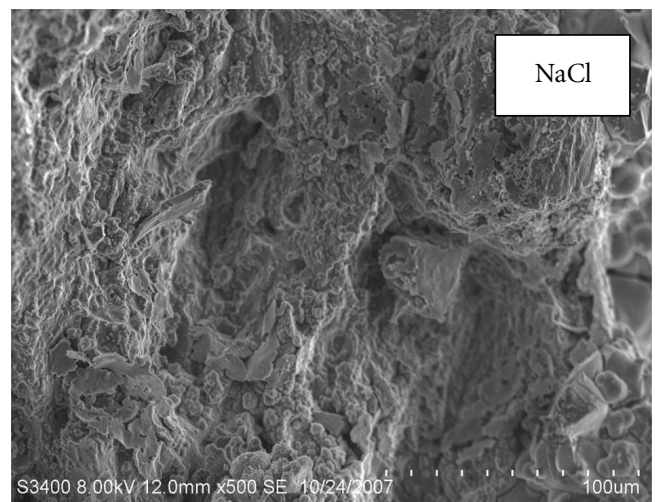

(d)

FIGURE 8: Fracture morphology of uncoated (a), (b), and PEO-coated (c), (d) AA7075 aluminum alloy specimens after SSRT in air and $\mathrm{NaCl}$.

TABle 1: Mechanical parameters obtained from SSRT tests at $5 \times$ $10^{-7} / \mathrm{s}$

\begin{tabular}{lccc}
\hline Sample & Medium & UTS (MPa) & \% Elongation \\
\hline \multirow{2}{*}{ Uncoated } & Air & 432 & 12.9 \\
& $\mathrm{NaCl}$ & 428 & 11.5 \\
\multirow{2}{*}{ PEO coated } & $\mathrm{Air}$ & 430 & 12.7 \\
& $\mathrm{NaCl}$ & 426 & 12.6 \\
\hline
\end{tabular}

the compact inner layer. Hence, the corrosion resistance of the PEO coating is mainly derived from the inner compact layer although the outer layer had pores in it.

3.4. Slow Strain Rate Tests (SSRTs). Figure 6 compares the stress-strain curves obtained for the uncoated (Figure 6(a)) as well as PEO-coated (Figure 6(b)) specimens that were tested in air and $\mathrm{NaCl}$ solution. The SSRT data such as UTS and $\%$ El. measured from the above plots, are summarized in Table 1. An examination of the stress-strain plots and the data in Table 1 shows that there was a reduction in elongation for the uncoated specimens in $\mathrm{NaCl}(11.5 \%)$ when compared to the one tested in air (12.9). With respect to the coated specimens, the values are comparable. However, no significant changes in UTS values were seen for both coated and uncoated specimens. The loss in tensile elongation (1.4\%) observed for the uncoated specimens suggests that the alloy may be susceptible to environmental cracking.

Figure 6 also shows that the elongation of the sample that was preexposed to $\mathrm{NaCl}$ solution without any load followed by SSRT test in air was less when compared to the sample continuously strained in $\mathrm{NaCl}$ solution.

Posttest metallographic observation of the uncoated sample after SSRT indicated severe pitting corrosion throughout the gauge length (Figure $7(\mathrm{a})$ ). Further examination after polishing and etching clearly reveals preferential attack of the coring and intermetallic phases promoting nucleation of cracks (Figure 7(b)). This observation along with the preexposure test results leads to the belief that the loss in tensile elongation observed for the uncoated sample may not be due to SCC. It can also be noted that the stereo macrograph of the coated sample after SSRT exhibited large number of microcracks as a result of SSRT test (Figure 7(c)). Fractographic examination of all the coated and uncoated tensile samples after SSRT revealed a typical ductile cracking morphology (Figures 8(a)-8(d)). This again confirms that the reduction in elongation of the uncoated samples in $\mathrm{NaCl}$ was to be due to corrosion-assisted mechanical failure rather than true SCC.

The results obtained in the present work demonstrated that the metallurgical heterogeneities such as coring and intermetallic phases present in the alloy forging resulted in a loss in tensile elongation of $1.4 \%$ in the $\mathrm{NaCl}$ solution and 
the same could be improved by PEO coating although to a marginal extent $(1.1 \%)$. However, the same coating was found to offer significant improvement in the general corrosion resistance. These results are in agreement with the reported results on magnesium alloys. The later results also reported that SCC was not completely eliminated by this $\mathrm{PEO}$ coating in spite of the marginal improvement. This was shown to be due to the numerous microcracks generated during straining of the sample in the corrosive environment. Hence, further work to be directed towards understanding the influence of various ions by modifying the bath composition and to render the coating more ductile in order to understand the real effect of such ceramic coating on the environmentally induced cracking behaviour of light alloys is needed.

\section{Conclusions}

Based on the results obtained by electrochemical corrosion and SSRT tests on alloy AA7075-T7351, the following conclusions were made.

(1) The metallurgical heterogeneities such a dendritic coring and intermetallic phases resulted in severe localized corrosion of this alloy causing significant reduction in elongation of the alloy forging under slow strain rate conditions in $3.5 \mathrm{wt}$. \% NaCl solution.

(2) PEO coating was found to be effective towards improving such localized corrosion promoted by metallurgical heterogeneities by providing good barrier resistance. However, the same coating under SSRT conditions resulted in the generation of microcracks. Despite the numerous surface cracks and pores existing on the outer layer of the coating, the tensile properties of the alloy were not deteriorated even in the corrosive environment.

(3) The deposited coating mainly consists of $\gamma-\mathrm{Al}_{2} \mathrm{O}_{3}$ phase. The absence of $\alpha-\mathrm{Al}_{2} \mathrm{O}_{3}$ phase in the coating could be due to the increased concentrations of $\mathrm{Mg}$ and $\mathrm{Zn}$ in the alloy substrate

(4) It is evident that the results obtained in the present work along with similar results published in the literature on magnesium alloys and PEO coating cannot be very useful especially for SCC resistance although it provided good general corrosion resistance. Hence, to understand the effectiveness of such coating, future work should be directed with modified bath composition so as to render crack tip passivation and to improve the ductility of the coating.

\section{Acknowledgments}

A. Venugopal, S. Manwatkar, and K. Sreekumar are grateful to Dr. P. P. Sinha, Deputy Director, MME, VSSC for the interest and encouragement shown in this work.

\section{References}

[1] M. O. Speidel, "Stress corrosion cracking of aluminium alloys," Metallurgical Transactions, vol. 6, no. 4, pp. 633-652, 1975.

[2] D. O. Sprowls and R. H. Brown, "Fundamental aspects of stress corrosion cracking," in Proceedings of the International Conference on Fundamental Aspects of Stress Corrosion Cracking, pp. National Association of Corrosion Engineers-1, R.W. Steahle, A.J. Forty, D. van Rooyen, Houston, Tex, USA, 1969.

[3] R. C. Dorward and K. R. Hasse, "Flaw growth in high strength $\mathrm{Al}-\mathrm{Zn}-\mathrm{Mg}-\mathrm{Cu}$ alloys exposed to stress corrosion environ ments," Corrosion, vol. 34, no. 11, pp. 386-395, 1978.

[4] J. K. Parker and A. J. Ardell, "Effect of retrogression and reaging treatments on the microstructure of aluminium 7075T651," Metallurgical Transactions, vol. 15, pp. 1531-1542, 1984.

[5] A. F. Oliveira Jr., M. C. de Barros, K. R. Cardoso, and D. N. Travessa, "The effect of RRA on the strength and SCC resistance on AA7050 and AA7150 aluminium alloys," Materials Science and Engineering A, vol. 379, no. 1-2, pp. 321-326, 2004.

[6] N. Birbilis, M. K. Cavanaugh, and R. G. Buchheit, "Electrochemical behavior and localized corrosion associated with $\mathrm{Al}_{7} \mathrm{Cu}_{2} \mathrm{Fe}$ particles in aluminum alloy 7075-T651," Corrosion Science, vol. 48, no. 12, pp. 4202-4215, 2006.

[7] P. S. Pao, S. J. Gill, and C. R. Feng, "On fatigue crack initiation from corrosion pits in 7075-T7351 aluminum alloy," Scripta Materialia, vol. 43, no. 5, pp. 391-396, 2000.

[8] T. M. Yue, L. J. Yan, C. F. Dong, and C. P. Chan, "Stress corrosion cracking behaviour of laser treated aluminium alloy 7075 using a slow strain rate test," Materials Science and Technology, vol. 21, no. 8, pp. 961-966, 2005.

[9] P. Bala Srinivasan, C. Blawert, W. Dietzel, and K. U. Kainer, "Stress corrosion cracking behaviour of a surface modified magnesium alloy," Scripta Materialia, vol. 59, pp. 43-46, 2008.

[10] P. Bala Srinivasan, C. Blawert, and W. Dietzel, "Effect of plasma electrolytic oxidation coating on the stress corrosion cracking behaviour of wrought AZ61 magnesium alloy," Corrosion Science, vol. 50, no. 8, pp. 2415-2418, 2008.

[11] P. B. Srinivasan, S. Riekehr, C. Blawert, W. Dietzel, and M. Koçak, "Slow strain rate stress corrosion cracking behaviour of as-welded and plasma electrolytic oxidation treated AZ31HP magnesium alloy autogenous laser beam weldment," Materials Science and Engineering A, vol. 517, no. 1-2, pp. 197-203, 2009.

[12] A. Ghasemi, V. S. Raja, C. Blawert, W. Dietzel, and K. U. Kainer, "Study of the structure and corrosion behavior of PEO coatings on AM50 magnesium alloy by electrochemical impedance spectroscopy," Surface and Coatings Technology, vol. 202, no. 15, pp. 3513-3518, 2008.

[13] J. A. Curran and T. W. Clyne, "Thermo-physical properties of plasma electrolytic oxide coatings on aluminium," Surface and Coatings Technology, vol. 199, no. 2-3, pp. 168-176, 2005.

[14] Y. J. Oh, J. I. Mun, and J. H. Kim, "Effects of alloying elements on microstructure and protective properties of $\mathrm{Al}_{2} \mathrm{O}_{3}$ coatings formed on aluminum alloy substrates by plasma electrolysis," Surface and Coatings Technology, vol. 204, no. 1-2, pp. 141$148,2009$.

[15] K. Tillous, T. Toll-Duchanoy, E. Bauer-Grosse, L. Hericher, and G. Geandier, "Microstructure and phase composition of microarc oxidation surface layers formed on aluminium and its alloys 2214-T6 and 7050-T74," Surface and Coatings Technology, vol. 203, no. 19, pp. 2969-2973, 2009. 
[16] W. Xue, C. Wang, H. Tian, and Y. Lai, "Corrosion behaviors and galvanic studies of microarc oxidation films on Al-ZnMg-Cu alloy," Surface and Coatings Technology, vol. 201, no. 21, pp. 8695-8701, 2007. 

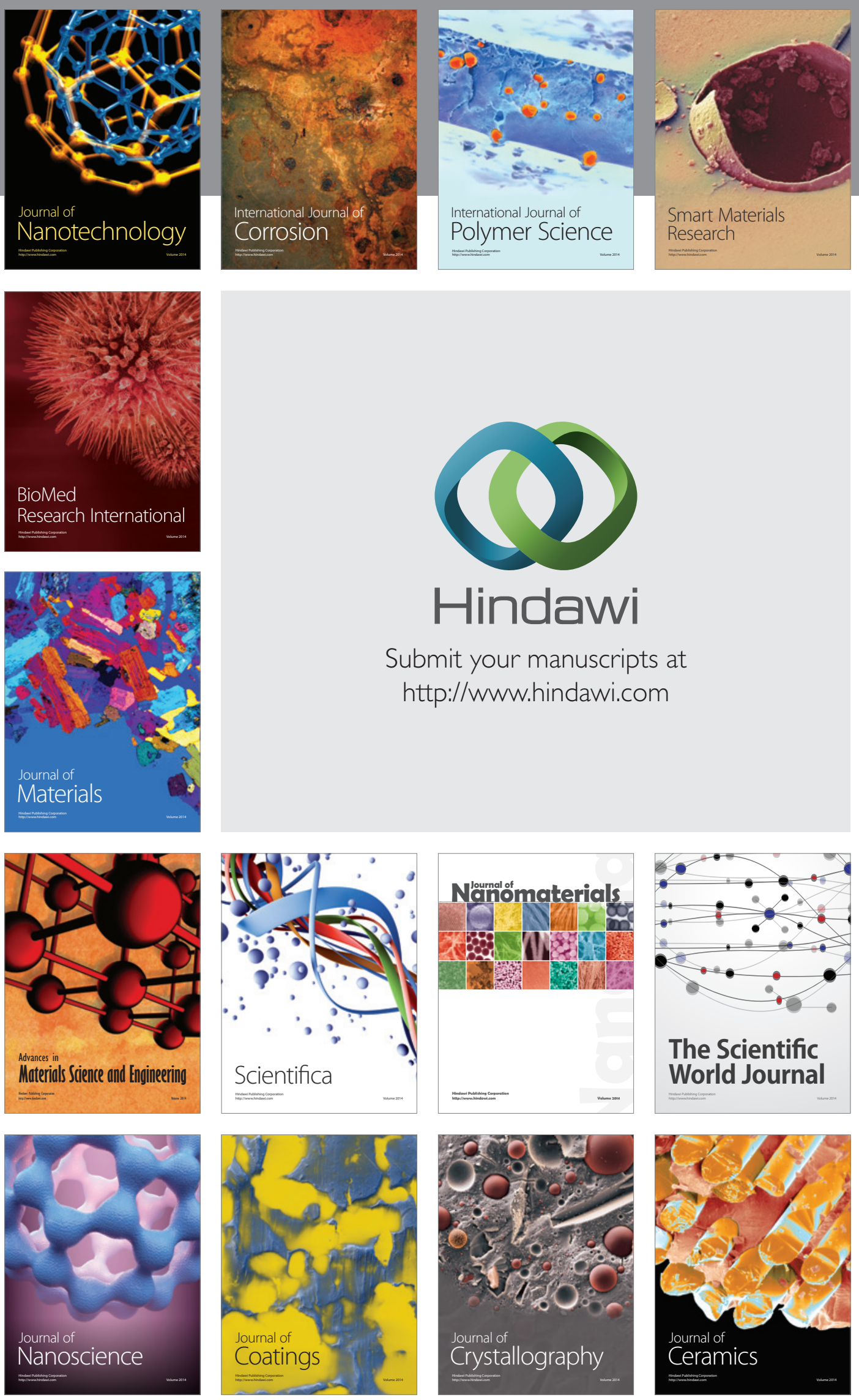

The Scientific World Journal

Submit your manuscripts at

http://www.hindawi.com

\section{World Journal}

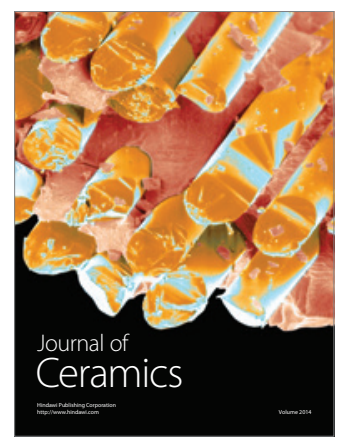

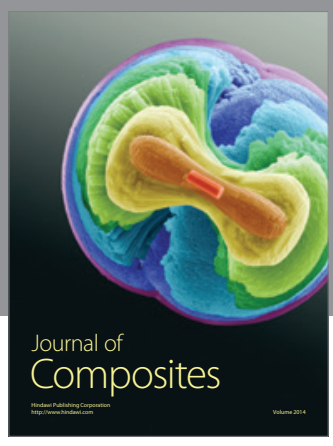
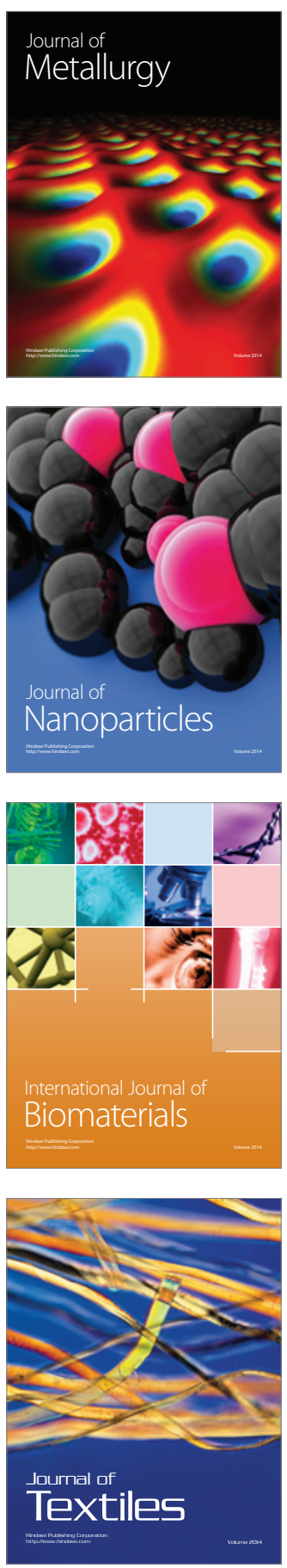